\title{
10
}

\section{Female-biased Parental Investment and Growth Performance among the Mukogodo}

\author{
LEE CRONK
}

One of the boldest predictions about behavior to come out of evolutionary biology is the idea that in certain circumstances parents should be expected to bias their investment in favor of one sex of offspring or the other. Previous work among the Mukogodo of Kenya (Cronk 1989b, 1990b, 1991b, 1993) has provided tentative support for this prediction in one human society, where parents appear to be biasing their investment in favor of daughters, who tend to have better marital and reproductive prospects than sons. This chapter reports on new research among the Mukogodo that both confirms and elaborates upon the earlier findings.

\section{THEORETICAL BACKGROUND}

Sex biases in parental investment and the closely related topic of sex ratio evolution have been important topics in evolutionary biological theory since Fisher (1934) explained why parents in a population should, on average, invest equally in sons and daughters. Fisher's reasoning was as simple as it was powerful. Because every individual in a sexually reproducing, diploid species gets half its nuclear genetic material from its mother and half from its father, selection should favor parents who invest equally in daughters and sons because a single unit of investment in an individual of one sex will have the same effect on a parent's fitness as a unit invested in the other sex.

Later theoreticians explored circumstances in which selection might favor individual parents who bias their investment in favor of one sex or another. Hamilton (1967), for example, examined circumstances in which siblings of one sex compete with one another for mates. In such situations, the competition makes individuals of the competitive sex more costly to produce from the point of view of the parents than individuals of the other sex, and so selection should favor parents who produce more of the other sex. Subsequently, others explored situations in which one sex of offspring is more expensive than the other because it competes 
with parents or siblings for resources (local resource competition; see Clark 1978), situations in which one sex of offspring is cheaper than the other because it provides resources that benefit parents or siblings (local resource enhancement; see Gowaty and Lennartz 1985), and situations in which one sex of offspring is cheaper because it enhances the mating success of parents or siblings (local mate enhancement; see Sieff 1990).

Those models are all essentially refinements of Fisher's principle in that they predict that overall parental investment in sons and daughters, including not only investments that parents can control but also those they cannot, will be equal (Cronk 1991b; see also Hoogland 1981). Robert Trivers and Dan Willard (1973) broke from this pattern by proposing that in some circumstances natural selection should favor parents within a population whose overall investment is truly biased in favor of one sex of offspring. Specifically, they hypothesized that where the reproductive prospects of sons and daughters differ in ways that can in some way be predicted from the situation of the parents, selection should favor parents who invest more heavily in the offspring with the better prospects. Among polygynous mammal species, for example, the variance in reproductive success is typically greater among males than among females, and so the conditions in which individuals are reared may have a greater impact on male than on female reproductive success. If an individual's rank, physical condition, or access to resources is affected by his or her parents' condition, then parents in good condition should favor sons because a very successful son will be more successful than a very successful daughter. Parents in poor condition, on the other hand, should favor daughters because an unsuccessful daughter will still be more successful than an unsuccessful son.

Though the Trivers-Willard hypothesis was greeted with skepticism (e.g., Williams 1979), eventually the effects it predicts were observed in a variety of nonhuman species (see Clutton-Brock and Iason 1986; Gray 1985; Hrdy 1987, 1988). Evolutionary Biology and Human Social Behavior: An Anthropological Perspective (Chagnon and Irons, eds. 1979) included some of the earliest tests of the model with data from human societies. Chagnon, Flinn, and Melancon (1979) tested the hypothesis among the Yanomamö, predicting that headmen and men who belong to larger lineages would have more male than female offspring. Their reasoning was that headmen are prestigious and respected individuals who have, on average, more than twice as many offspring as other men (Chagnon 1979) and that men in large lineages are at an advantage compared with men in smaller lineages because they have larger numbers of allies. Neither prediction was supported by the data. Chagnon and colleagues suggested that the failure of the model may be due to a lack of fit between the conditions that must be present for it to apply and the circumstances of the Yanomamö. Specifically, in that particular population there may be very little correlation between the size of a man's lineage or his individual status in the community and the reproductive prospects of his offspring. 
In that same volume, Mildred Dickemann presented data on male-biased parental investment from three historical societies that do seem to have the preconditions required by the Trivers-Willard model. Among the elites of feudal north India, imperial China, and medieval Europe, high-status males generally had better reproductive prospects than their sisters, and parents appear to have biased investment in favor of sons. The details of the male bias vary from case to case. In north India during the late seventeenth and early eighteenth centuries, for example, members of the ruling Jhareja subcaste reportedly killed almost all female infants. Female infanticide was also common among other high-status groups in that region while being rare or absent among lower-status groups. These two studies helped demonstrate the strength and promise of the new Darwinian paradigm in at least three ways. First, they showed the ability of the paradigm to direct researchers' attention to topics, such as sex biases in parental investment, that had previously received little attention from anthropologists. Second, they demonstrated the power of the new approach to help make sense of previously unexplained observations, such as the Indian infanticide data. Third, they demonstrated the determination of those working in this new field to adhere closely to the standards of scientific method, including Popperian falsificationism. This helped to set the stage for the study described in this chapter.

\section{THE MUKOGODO}

The Mukogodo are a low-status, impoverished group of Maasai-speaking pastoralists in north-central Kenya. Until early in the twentieth century, they were a relatively isolated group of hunter-gatherers and beekeepers. They lived in small rockshelters in the Mukogodo Hills, spoke a unique Eastern Cushitic language called Yaaku, and married among themselves, paying beehives as bride-wealth. As a result of population growth and population movements caused by British colonial policies, during the first few decades of the twentieth century the Mukogodo came into increasing contact with a variety of Maasai-speaking pastoralist groups, including not only large and famous groups like the Samburu and the Maasai themselves, but also smaller groups like the Digirri, Ilng'wesi, and Mumonyot. Intermarriage with Maasai-speakers, which always involved livestock rather than beehive bride-wealth payments, led to a situation in which Mukogodo males had to obtain livestock in order to get married. Subsequently, the Mukogodo rapidly lost their old way of life, including their old language, and adopted the language, culture, and subsistence patterns of their new Maasai-speaking neighbors (Cronk 1989a).

The Mukogodo transition to pastoralism transformed them from a group of relatively independent hunter-gatherers to the bottom stratum of a regional hierarchy of wealth, status, and marital success (Cronk 1990a). The transition was so recent that typical Mukogodo herd sizes are still far behind those of neighboring groups. 
Maasai-speakers look down on the Mukogodo and refer to them by the derogatory term il-torrobo because of their recent history as hunter-gatherers, a way of life considered suitable only for wild animals, and because until recently they spoke a language other than Maasai (see Galaty 1979 for details on the concept of il-torrobo). As a result of their poverty and low status, polygyny rates are lower and men's ages at first marriage are higher among the Mukogodo than among neighboring groups. However, the difficulties that Mukogodo men have in obtaining wives are not experienced by Mukogodo women, all of whom get married, often to men from wealthier neighboring groups.

\section{FEMALE-BIASED PARENTAL INVESTMENT}

The difference in the reproductive prospects of Mukogodo males and females sets the stage for a test of the Trivers-Willard hypothesis, which would predict that Mukogodo parents should favor daughters over sons. Between 1985 and 1987 I conducted fieldwork among the Mukogodo and collected data relevant to this prediction. The first hint that there might be female-biased parental investment came from their childhood (ages 0-4) sex ratio, which in 1986 was equivalent to 67 boys for every 100 girls. Although good data on the sex ratio at birth was impossible to come by owing to Mukogodo women's reticence to discuss child deaths, there seemed little reason to believe that the bias was due to any sort of physiological mechanism affecting the survivorship of male sperm or fetuses, and other data sources suggested that the sex ratio bias was due to unusually high male childhood mortality produced by greater parental solicitude toward daughters. For example, some data suggest that Mukogodo daughters may have been nursed longer than sons ( $p<0.10$; see Cronk 1989b, 1991b). Data from a local dispensary and a clinic run by Roman Catholic missionaries showed a statistically significant tendency for Mukogodo parents to take their daughters for medical care more often than their sons. This tendency did not appear among parents from neighboring Maasai-speaking groups. Those groups have been marrying each other and the Mukogodo since early in this century and are culturally almost indistinguishable from one another, making it highly unlikely that this is due to any cultural difference among the groups in, say, beliefs about childcare or about boys' and girls' needs for medical treatment.

All of these data support the predictions of the Trivers-Willard model: Mukogodo parents appeared to be favoring the sex with the best reproductive prospects. This does not, by itself, rule out other possible explanations. For example, it may be that Mukogodo parents favor daughters over sons not (or not only) because of their superior reproductive prospects, but rather (or also) because of the bridewealth payments they attract. If this were true, then men with more daughters from their first marriages should have more wives subsequently than men with few or no daughters from their first marriages, and men with more sisters should have 
more wives than men with few or no sisters, because of the ability of men to use the bride-wealth attracted by their daughters and sisters to obtain more wives for themselves. Neither prediction is supported by the data. In a sample of 220 Mukogodo men, there is a low (Pearson's coefficient $=0.111$ ) and statistically insignificant $(p$ [one-tailed] $=0.1$ ) relationship between numbers of daughters from their first marriages who survived to age 15 and their total numbers of wives. In fact, the mean number of wives for men with one or more daughters from their first marriages who survived to age 15 (1.320) is actually lower than the mean number of wives for men with no such daughters (1.333), though the difference is not statistically significant $(p>0.25)$. Similarly, only a very slight (Pearson's coefficient $=0.095)$ and statistically insignificant $(p=0.084)$ negative relationship was found between men's numbers of wives and their numbers of full sisters surviving to age $15(N=330)$. The lack of a relationship among these variables probably reflects the difficulty of Mukogodo poverty. Mukogodo men lend and borrow a great deal of livestock, and it may be the case that most Mukogodo men who receive livestock as bride-wealth must tend to their debts rather than use the windfall to obtain additional wives for themselves or their sons.

\section{CAREGIVER BEHAVIOR AND CHILDREN'S GROWTH PERFORMANCE}

The 1986 research established that there was reason to believe that the Mukogodo were favoring their daughters over their sons and that this behavior fit the predictions of the Trivers-Willard model. However, the limited measures of parental behavior and the lack of details about the effects of biased parental investment on the children themselves raised new questions. Accordingly, I returned to the Mukogodo from May through August of 1993 to explore the details of everyday childcare and their effects on boys' and girls' growth performance, health, and, ultimately, survivorship. To assess patterns of parental investment, I collected several different types of data, including systematic observations of the behaviors of caregivers and children, mothers' reports on their children's morbidity, and usage statistics for two local clinics. To assess children's growth performance, I collected basic anthropometric data, including recumbent length, weight, and head circumference.

\section{The Sample and Its Characteristics}

Upon arrival I surveyed all of the Mukogodo settlements within reasonable walking and driving distance of my home base at Kuri-Kuri Primary School, located about three kilometers outside the Mukogodo Division headquarters town of Don Dol. Parents were able to provide exact birth dates, which are often recorded on immunization record cards by the staffs of local clinics, for almost all of the youngest children in the area. For children with unknown birth dates, I used 
tooth eruption patterns to help estimate ages (Townsend and Hammel 1990). I also collected tooth eruption data for the children with recorded birth dates, and the close fit between age estimates based on tooth eruptions and those based on recorded birth dates was reassuring. Children under 30 months old were the intended focus of the study for two reasons, one practical and the other theoretical. On a practical level, tooth eruption patterns become unreliable as indicators of age after about 30 months. On a theoretical level, I wanted to concentrate my attention on the youngest children because they are the most dependent upon parental care and hence potentially the most vulnerable to variations in its quality and quantity. However, in order to achieve the desired sample size, two children slightly outside this age group, a girl aged 32 months and a boy aged 31 months, needed to be included as well. Good birth date information was available for both of those children. The twenty boys in the study ranged from five months to 31 months old, with a mean age of 17.5 months. The twenty girls ranged from one month to 32 months old, with a mean age of 11.35 months.

\section{The Focal Follow Data}

Using methods pioneered mainly by ethologists (e.g., Altmann 1974) and later adapted by human behavioral ecologists and anthropologists (Borgerhoff Mulder and Caro 1985; Gross 1984; Hames 1992), I conducted systematic behavioral observations, called "focal follows," on all forty children in the sample. At two separate randomly chosen times between 6:30 A.M. and 6:30 P.M., I arrived unannounced at the home of each child and conducted an hour of observations. The identity of each caregiver, caregiver behaviors, and the behaviors of the child were all checked off on prepared sheets every fifteen seconds, as indicated by a watch alarm that I muffled with a heavy cloth and carried in my shirt pocket. I recorded such caregiver behaviors as an estimate of the number of meters between the caregiver and the child, whether the caregiver was holding the child in his or her arms or in a sling, any touching of the child, any vocalizations directed toward the child, and other behaviors such as dressing, washing, and feeding. I recorded such child behaviors as position (lying, sitting, standing, etc.), vocalizations, crying, feeding, nursing, and sleeping. At the end of each hour of observations, I compensated the main caregiver in charge, usually the child's mother, with a small cash payment.

From the original observations I have derived three simple and straightforward indicators of caregiver solicitude: the mean distance between the caregiver and the child, the proportion of time the caregiver was observed holding the child, and the proportion of time the child was observed to be nursing. Of course, these are not meant to be seen as independent or completely separate measures of solicitude: a nursing child is usually being held, and a child who is either nursing or being held has a caregiver-child distance of zero. The means for all of these indicators are biased in favor of females (Table 10.1). This by itself is not surprising given that the females are younger, on average, than the males, and, of course, a few months 
Table 10.1. Means for a variety of measures of caregiver solicitude, based on two hours of focal follow observations of each child.

\begin{tabular}{|c|c|c|c|c|c|}
\hline & \multicolumn{3}{|c|}{ Distance $^{a}$} & \multirow[b]{2}{*}{$\begin{array}{c}\text { Child- } \\
\text { holding }\end{array}$} & \multirow[b]{2}{*}{ Nursing } \\
\hline & $\begin{array}{c}\text { All } \\
\text { caregivers }\end{array}$ & $\begin{array}{c}\text { Mothers } \\
\text { only }\end{array}$ & $\begin{array}{c}\text { Non- } \\
\text { mothers }\end{array}$ & & \\
\hline Boys & 1.153 & 1.139 & 1.373 & $32.3 \%$ & $4.3 \%$ \\
\hline Girls & 0.379 & 0.319 & 0.637 & $58.7 \%$ & $11.0 \%$ \\
\hline All children & 0.766 & 0.780 & 0.989 & $45.5 \%$ & $7.6 \%$ \\
\hline
\end{tabular}

$a$ Mean caregiver-child distance estimate, in meters.

$b$ Non-nursing observations only

$c$ Mean percent of time children were held by caregivers

$d$ Mean percent of time children were nursed.

Table 10.2. Regression coefficients for a variety of measures of caregiver solicitude.

\begin{tabular}{llcc}
\hline Dependent variable & Constant & $\begin{array}{c}\text { Regression coefficient } \\
\text { for age in months }\end{array}$ & $\begin{array}{c}\text { Regression coefficient } \\
\text { for sex }(0=\text { male, } \\
1=\text { female })\end{array}$ \\
\hline $\begin{array}{l}\text { Mean caregiver-child distance } \\
\quad \text { (one-tailed) }\end{array}$ & 0.633 & 0.030 & -0.592 \\
$\begin{array}{l}\text { Mean proportion of time } \\
\text { children were held }\end{array}$ & 0.012 & 0.014 & 0.004 \\
$p$ (one-tailed) & 0 & -0.016 & 0.165 \\
$\begin{array}{l}\text { Mean proportion of time } \\
\text { children were nursed }\end{array}$ & 0.144 & 0.002 & 0.03 \\
$\quad$ (one-tailed) & 0 & -0.006 & 0.032 \\
Proportion of time children were & 0.651 & 0 & 0.07 \\
$\quad \begin{array}{l}\text { cared for by their mothers } \\
p \text { (one-tailed) }\end{array}$ & 0 & -0.008 & -0.100 \\
& & 0.154 & 0.098 \\
\hline
\end{tabular}

can make a big difference in the amount of time a child is held or nursed. However, even when age is statistically factored out, a female bias in caregiver solicitude remains. Table 10.2 shows the beta coefficients yielded by regressions of the three indicators of solicitude against the children's ages in months and their sexes, coded as a dummy variable. Another way to approach this is to calculate the correlation between sex and the three indicators of solicitude while controlling for age. Such partial correlation coefficients are obtained by regressing both sex and the three indicators of solicitude against age, saving the residuals, and then calcu- 
lating the correlations between the residuals for sex and each of the indicators of solicitude. The partial correlation coefficients between sex and mean caregiverchild distance, proportion of time the child was held, and the proportion of time the child was nursed are $-0.417,0.303$, and 0.240 , respectively. In sum, even controlling for age, the females in the sample tended to be closer to their caregivers and tended to be held and nursed more often than the males in the sample. The focal follows also provide a window onto a possible sex bias in nursing behavior. Part of the reason why the average proportion of time spent nursing is lower for boys than for girls is that while only the oldest female in the sample was never observed to nurse, seven males, one as young as 13 months, were never observed to nurse.

The focal follows also provide information about who takes care of Mukogodo infants and toddlers. Primary caregiver observations are fairly evenly divided between mothers (49\%) and other individuals, most often the focal child's sister $(16 \%)$. Surprisingly, mothers cared for the boys in the sample slightly more than the girls. However, a regression of the proportion of time each child was observed to be cared for primarily by his or her mother against age and sex yields small and nonsignificant regression coefficients (see Table 10.2), and the partial correlation between sex and the proportion of time each child was cared for by his or her mother is low (-0.167). Interestingly, the sex difference in mean child-caregiver distance is present for both mothers and others (Table 10.1). Setting aside instances of nursing, which bias the caregiver-child distance figures in favor of mothers over other caregivers, mothers still tend to stay closer to the focal children than do other caregivers (Table 10.1), but only slightly. The absence of any large difference between the quality of care given by mothers and that of other caregivers matches the findings of Borgerhoff Mulder and Milton (1985) among the Kipsigis of western Kenya, where other caregivers actually tended to keep closer to infants than did mothers. In sum, there does not appear to be much of a difference in the care given by mothers and others, and so the proportion of time a child is cared for by his or her mother does not seem to be a very good indicator of solicitude. Therefore, the lack of any significant correlation between this variable and sex is not surprising.

\section{Morbidity and Medical Care Reports}

After I conducted an hour of focal follow observations on a child, I then asked the child's mother, if she was present, whether the child had been ill the day before and what, if any, treatment was given. The girls' mothers were available to answer this question after all focal follows. They reported that their daughters had been ill on the previous day $19(47.5 \%)$ times. Fourteen of those times (74\% of 19) they were taken for treatment to the clinics run by the local Roman Catholic mission or the local government. Five of those times (26\% of 19) they were given no treatment. The boys' mothers were available to answer this question at 37 of the 40 
focal follows of boys. They reported that their sons had been ill on the previous day 22 times ( $59 \%$ of 37). Seventeen of those times (77\% of 22 ) they were given treatment either at one of the local clinics (14 times) or with purchased, over-thecounter medicines ( 3 times). Five of those times (36\% of 22) they were given no treatment. None of these differences is statistically significant.

\section{Clinic and Dispensary Visits}

Data for 1992, the last complete year before the field season, were collected for several different categories of clinic and dispensary use. Mukogodo children were identified by their surnames. Table 10.3 shows data for visits by children ages $0-4$ from the Don Dol Roman Catholic dispensary. The Mukogodo figures are for the entire year, while the non-Mukogodo figures are for a random sample of 25 days from throughout the year. As in 1986, there is a male bias for the non-Mukogodo and a slight female bias for the Mukogodo, but the bias is no longer statistically significant $\left(\chi^{2}=1.904, p>.05\right.$; cf. Cronk 1989b). Table 10.4 shows the same sort

Table 10.3. Visits by children ages 0-4 to the Don Dol Roman Catholic dispensary, 1992, by ethnic group, sex and type of visit.

\begin{tabular}{|c|c|c|c|c|c|c|c|c|}
\hline & \multicolumn{4}{|c|}{ Mukogodo ${ }^{a}$} & \multicolumn{4}{|c|}{ Non-Mukogodo ${ }^{b}$} \\
\hline & \multicolumn{2}{|c|}{ Males } & \multicolumn{2}{|c|}{ Females } & \multicolumn{2}{|c|}{ Males } & \multicolumn{2}{|c|}{ Females } \\
\hline & $\mathrm{New}$ & Repeat & New & Repeat & New & Repeat & New & Repeat \\
\hline & Visit & Visit & Visit & Visit & Visit & Visit & Visit & Visit \\
\hline$n$ & 51 & 48 & 63 & 41 & 76 & 36 & 66 & 31 \\
\hline$N$ & \multicolumn{2}{|c|}{$99(49 \%)$} & \multicolumn{2}{|c|}{$104(51 \%)$} & \multicolumn{2}{|c|}{$112(53 \%)$} & \multicolumn{2}{|c|}{$97(47 \%)$} \\
\hline
\end{tabular}

a. All patients treated during 1992 ages 0-4 with recognizably Mukogodo surnames.

b. Based on a random sample of 25 days from throughout 1992 .

Table 10.4. Visits by children ages 0-4 to the Don Dol government clinic, 1992, by ethnic group, sex and type of visit.

\begin{tabular}{|c|c|c|c|c|c|c|c|c|}
\hline & \multicolumn{4}{|c|}{ Mukogodo ${ }^{a}$} & \multicolumn{4}{|c|}{ Non-Mukogodo ${ }^{b}$} \\
\hline & \multicolumn{2}{|c|}{ Males } & \multicolumn{2}{|c|}{ Females } & \multicolumn{2}{|c|}{ Males } & \multicolumn{2}{|c|}{ Females } \\
\hline & $\mathrm{New}$ & Repeat & New & Repeat & New & Repeat & New & Repeat \\
\hline & Visit & Visit & Visit & Visit & Visit & Visit & Visit & Visit \\
\hline$n$ & 71 & 39 & 67 & 38 & 57 & 9 & 34 & 14 \\
\hline$N$ & \multicolumn{2}{|c|}{$110(51 \%)$} & \multicolumn{2}{|c|}{$105(49 \%)$} & \multicolumn{2}{|c|}{$66(58 \%)$} & \multicolumn{2}{|c|}{$48(42 \%)$} \\
\hline
\end{tabular}

a. All patients treated during 1992 ages 0-4 with recognizably Mukogodo surnames.

b. Based on a random sample of 25 days from throughout 1992. 
of data, collected in the same way, from the local government-run clinic, showing a slight male bias in clinic use among the Mukogodo and a very strong male bias among non-Mukogodo. The male bias in government clinic use among the nonMukogodo is so strong that the Mukogodo figures are actually significantly female-biased (or at least less male-biased) in comparison $\left(\chi^{2}=4.00, p<.05\right)$. In sum, although the female bias in clinic and dispensary use among the Mukogodo does not appear to have been as strong in 1992 as in 1986, Mukogodo parents do not appear to have anything like the strong male bias shown by their neighbors.

\section{Anthropometry}

Following standard procedures (Frisancho 1990; Gibson 1990; Jelliffe and Jelliffe 1989), I collected a variety of standard anthropometric data. Here I will report on height (measured as recumbent length), weight, and head circumferences. The height and weight data were analyzed with the help of EpiInfo (CDC 1991), a computer program developed by the Centers for Disease Control that provides weight-for-age (WAZ), height-for-age (HAZ), and weight-for-height (WHZ) $z$ scores by comparing children's measurements to a standard body of reference data published by the National Center for Health Statistics (Department of Health, Education, and Welfare 1977a, 1977b). Those data are not assumed to represent ideal growth patterns; rather, they provide a benchmark against which we can compare the growth performance of children of different ages and sexes. Figure 10.1 shows the means for boys and girls for all three measures of growth performance. By all three measures, the girls appear to be doing better than the boys. The differences for WAZ $(t=2.394, p<.025)$ and WHZ $(t=2.161, p<.05)$ are statistically significant, though the difference for $\operatorname{HAZ}(t=1.611, p>.05)$ is not.

The head circumferences were compared with a body of reference data from the United States (Roche et al. 1987). The reference data are available for children at birth, at one month, at three months, and then at three-month increments up to twelve months, and at six-month increments after that. The sample children were compared to the data for the increment they had most recently passed. The results are inconclusive. The mean $z$-score for head circumferences is slightly greater for males than for females $(0.135$ vs. -0.727$)$, but the difference is not statistically significant $(p$ [one-tailed] $>.05)$.

\section{DISCUSSION}

My earlier work on sex-biased parental investment among the Mukogodo was a good example of chance favoring a prepared mind. When I originally began my research among them, I had no intention of looking at parental behavior and no hint that Mukogodo parents might favor one sex over the other. Fortunately, evo- 


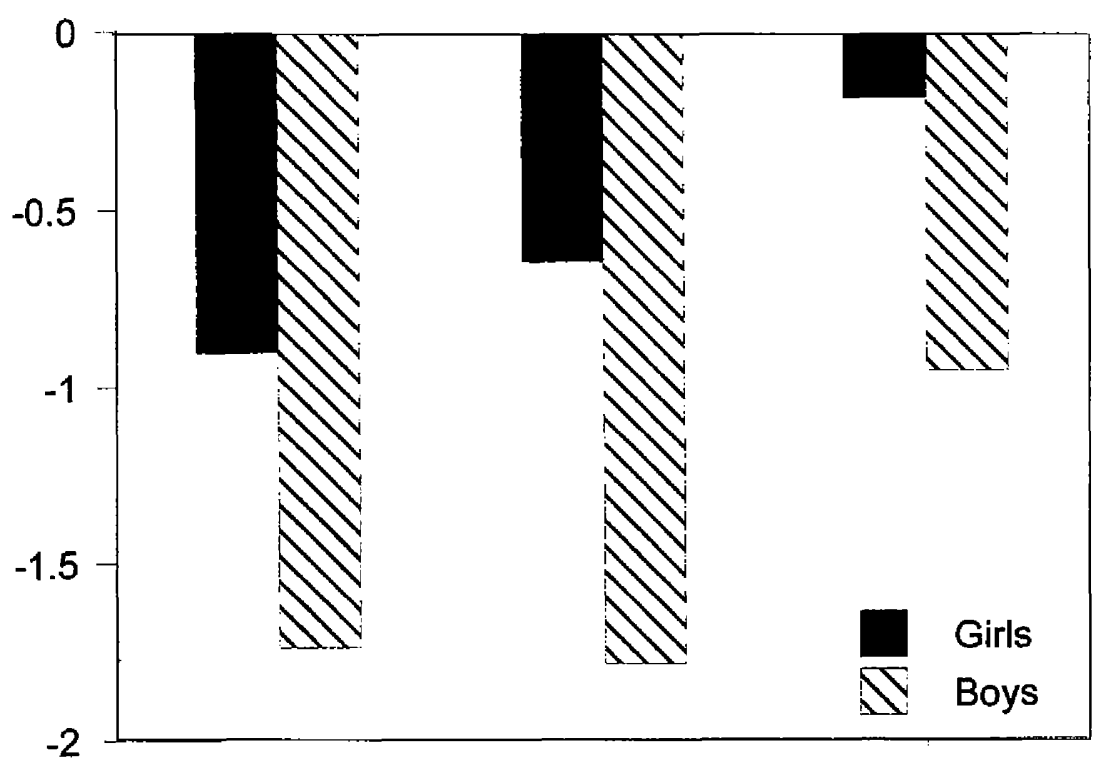

\section{Height for age Weight for age Weight for height}

Figure 10.1. Mean height-for-age (HAZ), weight-for-age (WAZ), and weight-for-height (WHZ) $z$-scores for boys and girls in the sample.

lutionary theories of sex ratios and parental investment had been parts of my education going back to my first undergraduate course in biological anthropology, and I immediately sat up and took notice when my first rough age-sex pyramid scribbled in my field notebook revealed such a strong female bias in the childhood sex ratio. The data that I subsequently gathered almost as an afterthought on dispensary and clinic use was enough to convince many people that the Mukogodo appeared to fit the predictions of the Trivers-Willard hypothesis.

The data collected in 1993 both corroborate and elaborate upon those from 1986. Mukogodo parents and other caregivers not only are more likely to provide girls than boys with medical treatment, they also hold and nurse daughters more and maintain less distance between themselves and girls than between themselves and boys. Possibly as a result of these biases in caregiver behaviors, Mukogodo girls appear to have significantly better growth performance than Mukogodo boys. Recent research in other societies suggests that such a female bias among lowerstatus groups may be relatively widespread. Bereczkei and Dunbar (1997) have shown that Hungarian Gypsy parents tend to invest more heavily in daughters than sons compared with other Hungarians, as indicated by the sex ratio at birth, duration of breast-feeding, length of education, and the likelihood that a birth of a girl 
or boy is followed by an abortion. In keeping with the predictions of the TriversWillard hypothesis, Gypsy parents have more grandoffspring through their daughters than through their sons, owing chiefly to a tendency toward hypergyny from that low-status group to higher-status non-Gypsy Hungarians. In a study of contemporary Americans, Gaulin and Robbins (1991) found that women with annual household incomes of less than $\$ 10,000$ or without an adult male present were more likely to breast-feed their daughters than their sons, and women without an adult male present tended to breast-feed their daughters an average of 5.5 months longer than their sons (see Cronk 1991b for more examples of female-biased parental investment possibly explained by the Trivers-Willard and other models).

This study also helps to address some of the criticisms that have been directed at the earlier one. For example, Sieff (1990:32) suggests that "it is conceivable that [Mukogodo] daughters were discriminated against in terms of food allocation and consequently became ill more often," leading their parents to take them to the local clinics more often. Neither the focal follow data on nursing frequencies nor the anthropometric data support the idea that Mukogodo boys are fed more generously than girls. Sieff (1990:32) also criticizes the fact that "the data on reproductive success of men versus women come from reproductive histories of adults while the evidence of investment favoring daughters comes from current children," but it is hard to imagine how it could be otherwise. Although natural selection would surely favor an ability among parents to be prescient about the reproductive prospects of their offspring were such an ability to arise, both phylogenetic constraints and, ultimately, the physical laws of our universe conspire to make this virtually impossible. All that Mukogodo parents and we researchers have to go on when gauging their offspring's reproductive potential is the way things are now. Thus, what Sieff identifies as a weakness of the study is actually one of its strengths.

Fix (1990:36) has a different problem with the earlier study: "what has evolved? Mukogodo parents of females might have more grandchildren than those with male offspring, but a hereditary bias for producing females could not increase through natural selection because there is no consistency across generations." As Sieff (1990:44) has explained, Fix assumes that the female bias is an obligate trait, while the bulk of research on sex-biased parental investment among both humans and nonhumans suggests that it is, in fact, a facultative trait. Even some insects have been shown to have the ability to facultatively alter the sex ratio of their offspring depending on local circumstances (e.g., Werren 1980). Given that the ability to adaptively adjust parental investment patterns has also been demonstrated among a variety of nonhuman primates and other mammals (see Clutton-Brock and Iason 1986), it is probably also a very ancient trait, shared not only by our entire species but also by a large clade of organisms of which humans are just a small part. The current situation among the Mukogodo may be helping to maintain this trait in our species, but I know of no one who has ever argued that the 
female bias observed there is either an obligate trait or isolated to the Mukogodo population.

Another criticism of this type of research is that sex ratios are population parameters, not phenotypes, and hence not subject to natural selection. Unless selection is in fact acting on sex ratios at the level of the population, an idea considered unlikely by most evolutionary biologists since the publication of Williams's (1966) critique of group selectionism, then this criticism is absolutely correct. This is why all of my work on the Mukogodo has been phrased in terms of sex-biased parental investment, not the female-biased Mukogodo childhood sex ratio, which is only a symptom of the underlying behavioral phenomenon postulated to be a product of selection. There is also another sense in which the femalebiased childhood sex ratio cannot be said to be either "adaptive" or "an adaptation." As far as can be determined, the sex ratio at birth among the Mukogodo is the same as most human populations, in other words, slightly male biased. Hence the female bias in the childhood sex ratio is most likely the result of an excessive number of deaths among male infants. Dead baby boys are not adaptive for Mukogodo parents, and I have no evidence at all that Mukogodo parents engage in deliberate infanticide. The deaths of their sons are one of the costs of their behavior, not a benefit. If Mukogodo parents could somehow keep their daughters as healthy as they do while also keeping more of their sons alive, surely they would do so. Their situation simply does not allow them that luxury.

Methodologically, this study helps to demonstrate the value of quantitative methods in the assessment of parental behavior and its effects. Casual observations and subjective impressions are no substitute for the systematic recording of behavior and careful physical measurements. My own subjective impressions when I conducted this fieldwork, for example, were that I would find no significant differences between the growth performances of Mukogodo boys and girls and that no significant differences in caregiver solicitude toward boys and girls would be discerned in the focal follow data. I was wrong on both counts. It is simply too easy for a casual observer, even one who is doing all of the anthropometric measurements and recording all of the caregiver behaviors, to fail to notice subtle differences between different children and caregivers.

Future studies of parental behavior will surely make further refinements in methodology. On a theoretical level, what is most needed now in this field is some clarification of the psychological mechanisms involved in sex-biased parental behavior. Specifically, it remains unclear what sorts of environmental cues parents are picking up on when they favor sons or daughters. One possibility is that they are looking at their condition, including their socioeconomic status, in a very general way, without any specific attention to the marital or reproductive prospects of their sons and daughters. Another possibility is that it is not the parents' overall condition that matters but simply their expectations about their sons' and daughters' reproductive prospects. The study of the Mukogodo does not help to clarify 
this because both possibilities could explain the behavior of Mukogodo parents: We have no way of telling whether Mukogodo parents are reacting to their overall socioeconomic status or to the relative marital and reproductive prospects of their daughters and sons. What are needed instead are studies in societies where socioeconomic status and the relative marital and reproductive prospects of daughters and sons have become disentangled. If, for instance, socioeconomic status is not a good predictor of the relative marital and reproductive prospects of sons and daughters in a particular society, but low-status parents still favor daughters and high-status ones still favor sons, this would suggest that it is socioeconomic pure and simple, rather than some estimation of the reproductive prospects of sons and daughters, that is the essential cue. None of the existing studies of sexbiased parental investment directly addresses this issue, but Gaulin and Robbins's (1991) study of poor American women suggests that low socioeconomic status alone may be enough to lead women to favor daughters over sons.

As I have advocated elsewhere (Cronk 1995, 1999) future research should also explore the role of culture in the production of parental behavior. The relationship between culture and behavior in general can be difficult to understand, and confusion about the meaning of the term "culture" does not help. Unfortunately, many common definitions of the term culture actually include the category of behavior, making it impossible to tease them apart so that culture can be used in a meaningful way to help explain behavior. Following the lead of some cognitive, symbolic, and hermeneutic anthropologists (see Keesing 1974), many advocates of an evolutionary approach to behavior have begun to advocate limiting the term "culture" to ideational elements (e.g., Barkow 1989; Cronk 1995, 1999; Durham 1992). The definition that I use is simple and limited: culture is simply a shorthand for socially transmitted information.

One window onto the culture of parenting is parents' stated sex preferences for children. Table 10.5 shows the responses Mukogodo women gave in 1986 and 1993 to a question about their desired family size and composition. The 1986 data were collected by Beth Leech during female reproductive history interviews with 121 Mukogodo women; the 1993 data were collected by Scola Ene Matunge during female reproductive history interviews with the mothers of the 40 children in

Table 10.5. Stated offspring sex preferences of Mukogodo women.

\begin{tabular}{lcc}
\hline Preference & 1986 & 1993 \\
\hline More boys & $14(12 \%)$ & $10(25 \%)$ \\
More girls & $9(7 \%)$ & $2(5 \%)$ \\
Even & $44(36 \%)$ & $12(30 \%)$ \\
No preference & $54(45 \%)$ & $16(40 \%)$ \\
Total & 121 & 40 \\
\hline
\end{tabular}


the sample. In both cases, most mothers have no sex preference, but those who do express a preference are more likely to say that they prefer sons than daughters. Furthermore, the two mothers who expressed a preference for daughters in 1993 may in fact have been expressing nothing of the kind. One of them was simply elaborating on the fact that she wanted no more children beyond the two daughters and one boy she already had, while the other was actually hoping that her next child would be both a boy and her last child, which would have given her more daughters than sons. These kinds of mismatches between parents' stated sex preferences for offspring and their behavior toward them may be quite common. In an earlier review of the literature on female-biased parental investment, stated preferences and behavior toward children did not match in either of the other societies (Ifaluk and Herero) for which both stated sex preferences of parents and data on parental care are available (Cronk 1991b; see Betzig and Turke 1986 and Burrows and Spiro 1957 for information on Ifaluk; see Pennington and Harpending 1993 for information on the Herero).

The stated male bias of Mukogodo parents may be surprising given the evidence about their actual behavior, but it is not surprising given the culture and beliefs of the Mukogodo and other Maasai-speakers. Maasai culture is very malebiased, and parents in Maasai-speaking groups routinely and openly express a preference for sons (see Jacobs 1973:403; Llewellyn-Davies 1981:339; Spencer 1965:211). The statements of preference for sons may be best understood not as genuine attempts to convey their own behavioral tendencies but rather as attempts to conform to the norms of Maasai-speakers and to send the message that the Mukogodo should be considered legitimate "Maasai" rather than il-torrobo. In short, the value of those statements may have more to do with manipulation of the impressions of others than with communication of information (see Cronk 1994a, 1994b, 1995; Dawkins and Krebs 1978; Krebs and Dawkins 1984 for more on this view of communication).

Additionally, intermarriage between the Mukogodo and neighboring groups is quite common, so many of the Mukogodo mothers included in these studies were raised among non-Mukogodo groups. This both makes their stated preferences more understandable and reduces the likelihood that the Mukogodo will ever develop a female-biased culture of parenting that matches their actual behavior. Furthermore, although many anthropologists and other social scientists may be tempted by the notion that evolutionary biology may have a role to play in the explanation of human universals but that explanations of behavioral variations among human societies must be only in terms of culture, this is a good example of the fact that behavioral variations can occur among human societies in the absence of cultural variation. Despite the fact that the Mukogodo and other Maasai-speaking pastoralists share a stated, culturally encoded bias in favor of sons, their actual behavior towards sons and daughters varies according to their particular situation. Given that such behavioral variations are routinely found among nonhuman 
species that do not have any significant amounts of culture, this really should not be surprising. If culture does have any role in the production of Mukogodo parental behavior, it may simply be in mitigating what otherwise would be an even stronger preference for daughters, as suggested by, for example, the data from the government-run clinic (Table 10.4).

\section{SUMMARY}

1. Previous research among the Mukogodo, a group of Maasai-speaking pastoralists in Kenya, has indicated that Mukogodo parents bias their investment in favor of daughters and that Mukogodo women have better marital and reproductive prospects than Mukogodo men.

2. Mukogodo favoritism toward daughters fits the prediction of the TriversWillard hypothesis that parents should bias investment in favor of the sex with the best reproductive prospects.

3. Data collected in 1993 confirm and elaborate upon the earlier findings. Mukogodo parents and other caregivers remain closer to girls than to boys, hold girls more than boys, and nurse girls more than boys. As in 1986, Mukogodo parents show a female bias when compared with parents from neighboring groups in their use of local medical facilities. The growth performance of Mukogodo girls is superior to that of Mukogodo boys, with significant differences in mean weightfor-age and weight-for-height $z$-scores.

4. The stated sex preferences of Mukogodo mothers are biased in favor of males, not females. This matches a male bias found in the cultures of all Maasaispeaking peoples and suggests that the female bias in Mukogodo parental behavior has little to do with culture. A comparison of the Mukogodo and other Maasai-speakers also provides a good example of behavioral diversity in the absence of cultural diversity.

\section{ACKNOWLEDGMENTS}

I would like to thank David Carlson, Kathy Dettwyler, Lore Guilmartin, Urs and Esther Herren, Paul Jamison, Becky Jobling, Beth Leech, Toshora Ole Lentolla, Peter Seem Ole Matunge, Scola Ene Matunge, Daniel Ole Matunge, Anna Lee Presley, Reniel Rodriguez Ramos, and Daniel Sellen for their help with this project. I especially appreciate the cooperation given to me by the Mukogodo, particularly the children in my sample and their mothers. I am also indebted to the Don Dol Roman Catholic Mission and the Kenyan government's clinic in Don Dol for access to their records. My 1986 fieldwork among the Mukogodo was made possible by funding from the National Science Foundation, the Population Council, and the Institute for Humane Studies. My 1993 fieldwork was funded by a Fulbright Grant and Texas A\&M University. Of course, I retain responsibility for any errors or shortcomings in this chapter. 


\section{REFERENCES}

Altmann, J. 1974. Observational study of behavior: Sampling methods. Behavior 48:1-41. Barkow, Jerome H. 1989. Darwin, Sex and Status: Biological Approaches to Mind and Culture. Toronto: University of Toronto Press.

Bereczkei, Tamas, and R. I. M. Dunbar. 1997. Female-biased reproductive strategies in a Hungarian Gypsy population. Proceedings of the Royal Society of London, Series B 264:17-22.

Betzig, Laura. L., and Paul W. Turke. 1986. Parental investment by sex on Ifaluk. Etholology and Sociobiology 7:29-37.

Borgerhoff Mulder, Monique, and T. Caro. 1985. The use of quantitative observational techniques in anthropology. Current Anthropology 25:323-335.

Borgerhoff Mulder, Monique, and M. Milton. 1985. Factors affecting infant care among the Kipsigis. Journal of Anthropological Research 41:231-262.

Burrows, E. G., and M. E. Spiro. 1957. An Atoll Culture: Ethnography of Ifaluk in the Central Carolines. Westport, Connecticut: Greenwood Press.

Centers for Disease Control and Prevention (CDC). 1991. Epi Info. Atlanta: Centers for Disease Control and Prevention.

Chagnon, Napoleon A. 1979. Is reproductive success equal in egalitarian societies? In Evolutionary Biology and Human Social Behavior: An Anthropological Perspective, Napoleon A. Chagnon and William Irons, eds. Pp. 374-401. North Scituate, Massachusetts: Duxbury Press.

Chagnon, Napoleon A., and William Irons, eds. 1979. Evolutionary Biology and Human Social Behavior: An Anthropological Perspective. North Scituate, Massachusetts: Duxbury Press.

Chagnon, Napoleon A., Mark V. Flinn, and Thomas F. Melancon. 1979. Sex-ratio variation among the Yanomamö Indians. In Evolutionary Biology and Human Social Behavior: An Anthropological Perspective, Napoleon A. Chagnon and William Irons, eds. Pp. 290-320. North Scituate, Massachusetts: Duxbury Press.

Clark, A. B. 1978. Sex ratio and local resource competition in a prosimian primate. Science 201:163-165.

Clutton-Brock, T. H., and G. R. Iason. 1986. Sex ratio variation in mammals. Quarterly Review of Biology 61:339-374.

Cronk, Lee. 1989a. From hunters to herders: Subsistence change as a reproductive strategy among the Mukogodo. Current Anthropology 30:224-234.

. 1989b. Low socioeconomic status and female-biased parental investment: the Mukogodo example. American Anthropologist 91:414-429.

. 1990a. Stratification, bride-wealth, and marriage patterns among the Mukogodo and their neighbors, Laikipia District, Kenya. Research in Economic Anthropology 12:89-109.

- 1990b. Comment on "Explaining biased sex ratios in human populations" by Daniela Sieff. Current Anthropology 31:35-36.

- 1991a. Intention vs. behaviour in parental sex preferences among the Mukogodo of Kenya. Journal of Biosocial Science 23:229-240.

. 1991b. Preferential parental investment in daughters over sons. Human Nature 2:387-417.

. 1993. Parental favoritism toward daughters. American Scientist 81:272-279.

1994a. Evolutionary theories of morality and the manipulative use of signals. Zygon: Journal of Religion and Science 29:81-101.

1994b. The use of moralistic statements in social manipulation: A reply to Roy A.

Rappaport. Zygon: Journal of Religion and Science 29:351-355. 
.1995. Is there a role for culture in human behavioral ecology? Ethology and Sociobiology 16(3):181-205.

- 1995. That Complex Whole: Culture and the Evolution of Human Behavior. Boulder, Colorado: Westview.

Dawkins, Richard, and John R. Krebs. 1978. Animal signals: Information or manipulation? In Behavioural Ecology: An Evolutionary Approach, first ed., John R. Krebs and N. B. Davies, eds. Pp. 282-309. Oxford: Blackwell Scientific.

Department of Health, Education and Welfare (HEW). 1977a. NCHS growth curves of children, birth-18 years, United States. Vol. 165. Series 11. Washington, D.C.: HEW, Public Health Service.

- 1977b. NCHS tables of growth, birth-18 years, United States. Vol. 124. Series 11. Washington, D.C.: HEW, Public Health Service.

Dickemann, Mildred. 1979. Female infanticide, reproductive strategies, and social stratification: A preliminary model. In Evolutionary Biology and Human Social Behavior: An Anthropological Perspective, Napoleon A. Chagnon and William Irons, eds. Pp. 321-367. North Scituate, Massachusetts: Duxbury Press.

Durham, William H. 1992. Coevolution: Genes, Culture, and Human Diversity. Stanford: Stanford University Press.

Fisher, R. A. 1934. The Genetical Theory of Natural Selection. Oxford: Clarendon.

Fix, Alan G. 1990. Comment on "Explaining biased sex ratios in human populations" by Daniela Sieff. Current Anthropology 31:36-37.

Frisancho, A. Roberto. 1990. Anthropometric Standards for the Assessment of Growth and Nutritional Status. Ann Arbor: University of Michigan Press.

Galaty, John G. 1979. Pollution and pastoral anti-praxis: The issue of Maasai inequality. American Ethnologist 6:803-816.

Gaulin, S. J. C., and C. J. Robbins. 1991. Trivers-Willard effect in contemporary North American society. American Journal of Physical Anthropology 85:61-69.

Gibson, R. 1990. Principles of Nutritional Assessment. New York: Oxford University Press.

Gowaty, P. A., and M. R. Lennartz. 1985. Sex ratios of nestling and fledging red-cockaded woodpeckers (Picoides borealis) favor males. American Naturalist 126:347-353.

Gray, J. Patrick. 1985. Primate Sociobiology. New Haven: HRAF Press.

Gross, D. 1984. Time allocation: A tool for the study of cultural behavior. Annual Review of Anthropology 13:519-558.

Hames, Raymond. 1992. Time allocation. In Evolutionary Ecology and Human Behavior, Eric Alden Smith and Bruce Winterhalder, eds. Pp. 203-235. New York: Aldine de Gruyter.

Hamilton, William D. 1967. Extraordinary sex ratios. Science 156:477-488.

Hoogland, J. L. 1981. Sex ratio and local resource competition. American Naturalist 117:796-797.

Hrdy, S. B. 1987. Sex-biased parental investment among primates and other mammals: A critical evaluation of the Trivers-Willard hypothesis. In Child Abuse and Neglect: Biosocial Dimensions, R. J. Gelles and J. B. Lancaster, eds. Pp. 97-147. New York: Aldine de Gruyter.

- 1988. Daughters or sons? Natural History 97(4):63-83.

Jacobs, A. 1973. The pastoral Maasai of Kenya and Tanzania. In Cultural Source Materials for Population Planning in East Africa, Vol. 3: Beliefs and Practices, A. Molnos ed. Nairobi: East African Publishing House.

Jelliffe, D., and E. Jelliffe. 1989. Community Nutritional Assessment with Special Reference to Less Technically Developed Countries. New York: Oxford University Press.

Keesing, Roger. 1974. Theories of culture. Annual Review of Anthropology 3:73-97. 
Krebs, John R., and Richard Dawkins. 1984. Animal signals: Mind reading and manipulation. In Behavioral Ecology: An Evolutionary Approach, second ed., John R. Krebs and N. B. Davies, eds. Pp. 380-402. Oxford: Blackwell Scientific.

Llewellyn-Davies, M. 1981. Women, warriors, and patriarchs. In Sexual Meanings: The Cultural Construction of Gender and Sexuality, S. B. Ortner and H. Whitehead, eds. Pp. 330-358. Cambridge: Cambridge University Press.

Pennington, Renee, and Henry Harpending. 1993. The Structure of an African Pastoralist Community: Demography, History, and Ecology of the Ngamiland Herero. Oxford: Clarendon.

Roche, Alex F., Debabrata Mukherjee, Shumei Gui, and William H. Moore. 1987. Head circumference reference date: Birth to 18 years. Pediatrics 79(5):706-712.

Sieff, Daniela F. 1990. Explaining biased sex ratios in human populations: A critique of recent studies. Current Anthropology 31:25-48.

Spencer, P. 1965. The Samburu. London: Routledge and Kegan Paul.

Townsend, Nicholas, and E. A. Hammel. 1990. Age estimation from the number of teeth erupted in young children: An aid to demographic surveys. Demography 27(1):165-174.

Trivers, Robert L., and D. E. Willard. 1973. Natural selection of parental ability to vary the sex ratio of offspring. Science 179:90-92.

Werren, J. H. 1980. Studies in the Evolution of Sex Ratios. Ph.D. dissertation, University of Utah, Salt Lake City.

Williams, G. C. 1966. Adaptation and Natural Selection. Princeton: Princeton University Press

1979. The question of adaptive sex ratios in outcrossed vertebrates. Proceedings of the Royal Society of London, Series B 205:567-580. 